Note

\title{
Use of Rice Bran for Preparation of GABA ( $\gamma$-aminobutyric acid)-rich Sourdough
}

\author{
Sook-Young KIM ${ }^{1}$, Ki Ju KIM ${ }^{2}$, Hyun-Chae $\mathrm{CHUNG}^{3}$ and Gi Dong HAN ${ }^{1 *}$ \\ ${ }^{I}$ Department of Food Science and Technology, College of Life Applied Science, Yeungnam University, Gyeongsan \\ 38541, Republic of Korea \\ ${ }^{2}$ Department of Vocational Rehabilitation, Daegu future College, Daegu 712-716, Republic of Korea \\ ${ }^{3}$ Division of Food, Beverage \& Culinary Arts, Yeungnam University College, Daegu 705-703, Republic of Korea
}

Received July 6, 2016 ; Accepted October 27, 2016

\begin{abstract}
Preparation of GABA ( $\gamma$-aminobutyric acid)-rich sourdough using rice bran and raisin was investigated. Preparation of sourdough began with pre-fermented raisin liquid, which is a widely used source of wild yeast and lactic acid bacteria. The number of naturally occurring cells in the liquid was $3.5 \times 10^{7} \mathrm{CFU} / \mathrm{mL}$ for yeast cells and 3.4 $\times 10^{7} \mathrm{CFU} / \mathrm{mL}$ for lactic acid bacteria. The liquid was added to rice bran and then used to make sourdough via a three-stage fermentation process for 42 hours. The numbers of yeast $\left(2.1 \times 10^{8} \mathrm{CFU} / \mathrm{g}\right)$ and lactic acid bacteria $\left(1.3 \times 10^{8} \mathrm{CFU} / \mathrm{g}\right)$ in sourdough increased gradually with repeated fermentation. We also confirmed that the GABA and polyphenol contents of sourdough significantly increased during fermentation. Thus, sourdough enriched with GABA could be rapidly and easily obtained through a three-stage natural fermentation process using rice bran and raisin. These findings also provide useful information for the effective use of milling rice by-products.
\end{abstract}

Keywords: rice bran, sourdough, $\gamma$-aminobutyric acid, polyphenols, fermentation

\section{Introduction}

Commercialization of sourdough bread is difficult since activation of yeast is time-consuming, and a high level of technology is required to produce standardized bread. However, as yeast fermentation technologies have become standardized, sourdough production has gradually reached its practical potential (Hamelman 2004; Chung et al., 2011; Cho et al., 1999). Current features of sourdough include improvement of unique flavors using naturally obtained bacteria (Thiele et al., 2002; Kim, 2001) and a prolonged storage period (Beak, 1990). Activation of natural yeast is a very important process. In general, sourdough starters are made from rye or fermented liquid using raisins. In other words, the process of sourdough development or standardization is considered to be one of the most important processes for making sourdough bread.

Previous studies on natural sourdough bread have focused on the separation of fermentation microorganisms from the bioactivity of sourdough (Banu et al., 2010; Chung et al., 2011), making of sourdough bread using hongguk (red ricefermented Monascus sp.) (Lee et al., 2007), and the development of starters using probiotics and Saccharomyces cerevisiae (Chae et al., 2011). Likewise, the main ingredients used to make sourdough are mostly derived from edible agricultural products such as wheat flour, rye flour, or functional materials.

We first gained evidence of the superiority of rice bran while seeking materials for the development of new sourdough starters (Bhanwar et al., 2013; Moon et al., 2010; Kwak, 2010; Leventhal et al., 2003). We learned that rice bran, a by-product of the rice milling process, is often disposed of without any further use except as an animal feed, even though it contains various bioactive materials such as phenolic compounds and GABA. Functional activities of GABA are known to include 
protective effects against streptozotocin-induced diabetes, cardiovascular diseases, stimulation of alcohol metabolism, and prevention of obesity (Nakagawa T et al., 2005; Lin KH et al., 2014; Stanley BG, 2012). In recent years, interest in GABA as a functional material for bread making has increased. Bhanwar S. et al., (2013) suggested Lactococcus lacitis as a lactic acid bacteria starter for the production of GABA-enriched bhatura (fried sourdough bread), but there has been little research on GABA-rich sourdough made from fermented rice bran and raisin liquid.

Based on these findings, this study investigated the efficacy of natural GABA-rich sourdough made from rice bran and raisins.

\section{Materials and Methods}

Raw materials Rice bran was prepared fresh by processing Brown-gaba rice through a rice milling machine within 7 days and purchased from an organic farm (Gyeongsan, Korea). Raisins used in this study were a product of Liberty Farms and Sales (TS corporation co., Ltd, Korea), wheat flour was hard flour (Daehan flour co., Korea), and sugar was white sugar (CJ Cheiljedang co., Korea). All other materials were used after purchase from a nearby market.

Analysis of physicochemical property The $\mathrm{pH}$ level was measured using a $\mathrm{pH}$ meter (Corning $\mathrm{pH}$ meter 240, U.S.A.) applied to $10 \mathrm{~mL}$ of raisin liquid, and the measurement was carried out three times (A.O.A.C, 1984). Measurement of acidity was performed using $10 \mathrm{~mL}$ of raisin liquid according to the method of AACC 2 to 31 (A.A.C.C., 1983). Briefly, raisin liquid was placed into a $250 \mathrm{~mL}$ beaker and diluted $10-$ fold with distilled water, after which two to three drops of $0.1 \%$ phenolphthalein indicator were added. The raisin liquid was then titrated with $0.1 \mathrm{~N} \mathrm{NaOH}$, and the endpoint was designated as the point at which pink color persisted for 30 seconds. The sugar content was measured three times using an Abbe Refractometer (Hand Refractometer, ATAGO, Japan).

Microbe count Yeast colonies were counted after cultivation at $30{ }^{\circ} \mathrm{C}$ for 48 hours on potato dextrose agar media (Difco, USA) to which $10 \%$ sterile tartaric acid was added in order to lower the $\mathrm{pH}$ of the medium to 3.5 , so that bacterial growth is inhibited. Colonies of lactic acid bacteria were counted after cultivation at $30{ }^{\circ} \mathrm{C}$ for 48 hours on Lactobacilli MRS media (Difco, USA) to which $0.01 \%$ Bromocresol green was added (Oberg et al., 1986).

Analysis of total phenolics and GABA The content of total phenolic compounds was measured according to the methods of Folin and Denis (Folin and Denis, 1912) and Lee et al (Lee et al., 2006). Dough was used after adjustment of density to $1 \mathrm{mg} / \mathrm{mL}$ with distilled water. Folin-Ciocalteu's reagent (0.2 mL; Sigma, U.S.A.) was added after mixing $0.2 \mathrm{~mL}$ of sample with $1.8 \mathrm{~mL}$ of distilled water in a screw tube. Absorbance was measured at $725 \mathrm{~nm}$ as follows: sample was incubated at room temperature for 3 minutes, followed by vortexing, addition of $0.4 \mathrm{~mL}$ of $10 \% \mathrm{Na}_{2} \mathrm{CO}_{3}$, and addition of $1.4 \mathrm{~mL}$ of distilled water for 1 hour. The content of total phenolic compounds was calculated from the standard curve using ferulic acid (Sigma, U.S.A.)

GABA content was measured by diluting $5 \mathrm{~g}$ of dough or fermented rice bran 10 times with distilled water, addition of $20 \mathrm{~mL}$ of distilled water, and addition of $20 \mathrm{~mL}$ of $20 \%$ TCA (trichloroacetic acid), after which the precipitated protein was centrifuged at 3,000 rpm for 20 minutes. The aqueous layer was decompressed and concentrated after addition of $30 \mathrm{~mL}$ of ethyl ether to the supernatant. After mixing, TCA and fatsoluble substances were removed. Citrate buffer $(0.2 \mathrm{M}$; $\mathrm{pH}$ 2.2) solution was added to the concentrate to a total volume of $5 \mathrm{~mL}$, filtered through a $0.22 \mu \mathrm{m}$ membrane filter, and analyzed using an amino acid analyzer (L-8800, Hitachi, Ltd., Tokyo, Japan). The fermented rice bran mentioned above was prepared according to the procedure of a previous study (Kim and Han, 2011). Briefly, distilled water was added to the rice bran at about $25 \%(\mathrm{v} / \mathrm{w})$ and then fermented with yeast of Issatchenkia orientalis MFST1 at RT for 5 days.

Preparation of fermented raisin liquid and rice bran sourdough Raisin mixture was prepared by adding $500 \mathrm{~g}$ of raisins to a sterile bottle, followed by mixing with $750 \mathrm{~mL}$ of sterile water and $10 \mathrm{~g}$ of sugar. The mixture was then kept in an incubator (HB- 201SLI Han Baek Scientific co., Korea) at $28{ }^{\circ} \mathrm{C}$ for 7 days and then filtered through a 60 -mesh sieve to produce fermented liquid.

Rice bran sourdough was prepared and cultured using a modified multi-stage method, as shown in Table 1. A threestage fermentation process was required to manufacture sourdough, and the endpoint of fermentation was the point at which when the volume of dough became twice that of the original. Specifically, primary sourdough was manufactured using a stationary culture of $250 \mathrm{~g}$ of rice bran, $250 \mathrm{~g}$ of bread flour, and $500 \mathrm{~g}$ of fermented raisin liquid in a fermenter (HS5001, Hwasung Machinery Co., Korea) at $28^{\circ} \mathrm{C}$. Secondary sourdough was manufactured using a stationary culture of $900 \mathrm{~g}$ of the primary sourdough with $450 \mathrm{~g}$ of rice bran, $450 \mathrm{~g}$ of flour, and $900 \mathrm{~g}$ of water at $28^{\circ} \mathrm{C}$. Final sourdough was manufactured using a stationary culture of $2,400 \mathrm{~g}$ of the secondary sourdough with 1,200 $\mathrm{g}$ of rice bran, 1,200 $\mathrm{g}$ of flour, and $1,680 \mathrm{~g}$ of water at $28{ }^{\circ} \mathrm{C}$. This experiment for making sourdough through three-stage fermentation using rice bran and raisin was carried out two times independently in same condition.

We confirmed a high reproducibility in the two times sourdough experiments with qualitatively similar results, and then we analyzed the results obtained from the last sourdough experiment.

Statistical analysis Data were obtained from triplicate measurement with three independent sampling from sourdoughs. Values are expressed as mean \pm standard deviation (SD). One-way analysis of variance (ANOVA) and T-test were 
Table 1. Sourdough mixing formula for multiple-stage dough method

\begin{tabular}{ccccccc}
\hline Samples & $\begin{array}{c}\text { Fermented } \\
\text { dough }\end{array}$ & $\begin{array}{c}\text { Fermented } \\
\text { raisin liquid (g) }\end{array}$ & Rice bran (g) & Flour (g) & Water (g) & Total (g) \\
\hline 0-step & - & 500 & 250 & 250 & 0 & 1000 \\
1-step & - & 500 & 250 & 250 & 0 & 1000 \\
2-step & 900 & - & 450 & 450 & 900 & 2700 \\
\hline 3-step & 2400 & - & 1200 & 1200 & 1680 & 6480 \\
\hline
\end{tabular}

Dough mixed with fermented raisin liquid and rice bran (0-step), dough after 24 hours of fermentation from 0-step (1-step), dough after 12 hours of fermentation from 1-step (2-step), and dough after 6 hours of fermentation from 2-step (3-step).

used for multiple comparisons. Treatment effects were analyzed using Duncan's multiple range test using SPSS 19.0 software. Differences are considered significant with $\mathrm{p}$ values $<0.05$.

\section{Results and Discussion}

Physicochemical properties and microorganism conditions of fermented raisin liquid Figure 1 (A) shows the $\mathrm{pH}$ and acidity results after fermenting raisins for 7 days. The $\mathrm{pH}$ level gradually decreased at the beginning of fermentation and then significantly decreased from day 5 of fermentation to a final $\mathrm{pH}$ level of 3.68. These results are consistent with the research results of Kim and Chun (Kim and Chun, 2008), who showed that the $\mathrm{pH}$ level decreases while acidity increases with a longer cultivation time of raisins. The acidity gradually increased over 7 days of fermentation after its significant increase on day $1(p<0.001)$. Changes in sugar content of the fermented liquid are shown in Fig. 1 (B). Sugar content significantly increased to 30.8 brix on day 1 of fermentation and gradually decreased as fermentation progressed, reaching a low point of 19.76 brix on day 7 . These results suggest that the sugar in raisins was used by microbes during fermentation, resulting in increased acidity and decreased $\mathrm{pH}$ level. According to Kim and Chun (Kim and chun, 2008), the sugar content of sourdough continuously increased until day 2 of fermentation, after which it gradually decreased from day 3 . In this study, sugar content gradually decreased after reaching its highest level on day 1 .

The numbers of naturally occurring yeast cells and lactic acid bacteria in the final fermented raisin liquid were determined. The numbers of lactic acid bacteria and yeast cells were similar at $7.531 \log _{10} \mathrm{CFU} / \mathrm{g}\left(3.4 \times 10^{7} \mathrm{CFU} / \mathrm{mL}\right)$ and 7.531 $\log _{10} \mathrm{CFU} / \mathrm{g}\left(3.5 \times 10^{7} \mathrm{CFU} / \mathrm{mL}\right)$, respectively (Table 2 Raisin F-L).

Fermentation time of sourdough added with rice barn was reduced by three-stage fermentation Primary sourdough was made by adding rice bran and flour to the fermented raisin liquid after fermentation for 7 days, whereas secondary sourdough was made by fermentation after addition of rice bran, flour, and water to the primary sourdough. Final

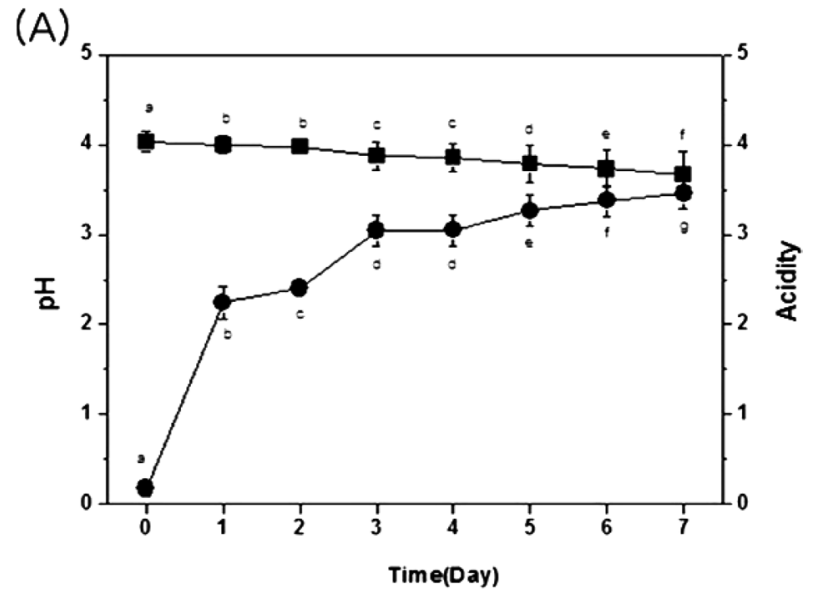

(B)

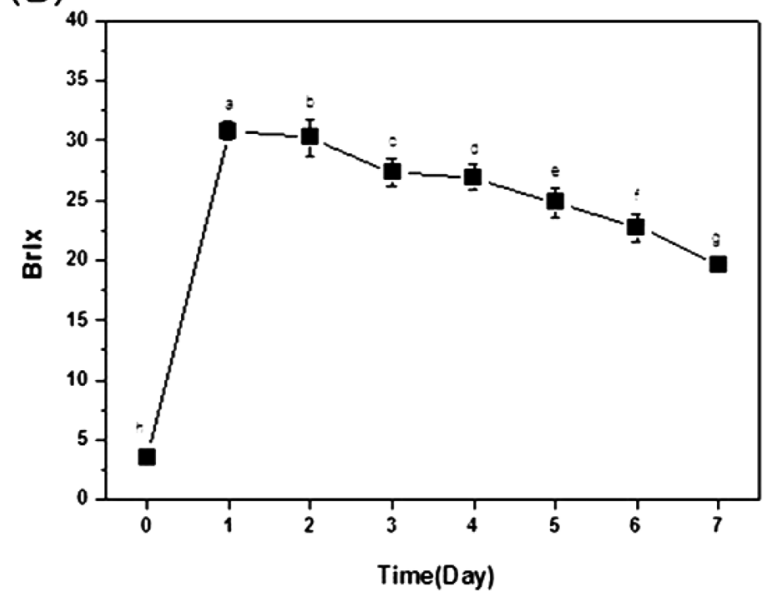

Fig. 1. Changes in $\mathrm{pH}$, acidity, and Brix in fermented raisin liquid. (A) $\mathrm{pH}(-\mathbf{-}-)$, Acidity (--). (B) Brix $(-\mathbf{-}-)$. Each value represents mean $\pm \mathrm{SD}(\mathrm{n}=3),{ }^{\mathrm{a}-\mathrm{f}}$ Means with different superscripts are significantly different at a $5 \%$ significance level by Duncan's multiple range test. F-value of $\mathrm{pH}$ is $191.006^{* * *}$, F-value of acidity is $14457.033 * * *(* * * p<0.001)$.

sourdough was made by fermentation after addition of rice bran, flour, and water to the secondary sourdough. Each stage of the fermentation process was carried out when the volume of dough reached twice that of the original. The time required 
Table 2. Changes in numbers of yeast cells and lactic acid bacteria of fermented raisin liquid and sourdough added with rice bran ( Unit: $\log 10 \mathrm{CFU} / \mathrm{g}$ )

\begin{tabular}{cccccc}
\hline & Raisin F-L & 0-step & 1-step & 2-step & 3-step \\
\hline $\begin{array}{c}\text { Yeast cells } \\
\begin{array}{c}\text { Lactic acid } \\
\text { bacteria }\end{array}\end{array}$ & $7.531 \pm 0.30^{\mathrm{bc}}$ & $7.505 \pm 0.50^{\mathrm{bc}}$ & $7.114 \pm 0.30^{\mathrm{c}}$ & $8.079 \pm 0.20^{\mathrm{ab}}$ & $8.322 \pm 0.09^{\mathrm{a}}$ \\
& & & & & \\
\end{tabular}

Fermented raisin liquid (Raisin F-L), dough mixed with fermented raisin liquid and rice bran (0-step), dough after 24 hours of fermentation from 0-step (1-step), dough after 12 hours of fermentation from 1-step (2-step), and dough after 6 hours of fermentation from 2-step (3-step). Each value represents mean $\pm \mathrm{SD}(n=3),{ }^{\mathrm{a}-\mathrm{d}}$ Means with different superscripts are significantly different at $5 \%$ significance level by Duncan's multiple range test. F-value of yeast cell is $7.265^{* *}, \mathrm{~F}$-value of Lactic acid bacteria is $6.082^{* *}$. $(* * p<0.01)$.

for the 1-step fermentation of sourdough was about 24 hours, 12 hours for 2 -step, and 6 hours for 3-step. Thus, the time required to ferment sourdough was reduced by half with each additional step to obtain the same volume of dough, indicating this three-step process efficiently reduced the time required to prepare sourdough.

Changes in microorganisms during fermentation of sourdough with adding rice bran Changes in yeast and lactic acid bacteria during fermentation of sourdough with added rice bran are shown in Table 2. The number of yeast colonies in the fermented raisin liquid was $7.531 \log _{10} \mathrm{CFU} / \mathrm{g}\left(3.5 \times 10^{7} \mathrm{CFU} /\right.$ $\mathrm{g}$ ), whereas the number slightly decreased to $7.114 \log _{10} \mathrm{CFU} / \mathrm{g}$ $\left(1.3 \times 10^{7} \mathrm{CFU} / \mathrm{g}\right)$ after addition of rice bran and flour in the 1 -step fermentation. The numbers of yeast colonies in the second and final step sourdoughs increased to $8.079 \log _{10} \mathrm{CFU} /$ g $\left(1.2 \times 10^{8} \mathrm{CFU} / \mathrm{g}\right)$ and $8.322 \log _{10} \mathrm{CFU} / \mathrm{g}\left(2.1 \times 10^{8} \mathrm{CFU} / \mathrm{g}\right)$, respectively, upon addition of rice bran and flour. The pattern of lactic acid bacteria in sourdough was similar to that of yeast as shown above. Based on these results, the numbers of yeast and lactic acid bacterial colonies continuously increased upon addition of rice bran and flour. Similarly, Hanne and Ase (Hanne and Ase, 2000) measured the numbers of yeast and lactic acid bacterial colonies to be 6.0-8.04 $\log _{10} \mathrm{CFU} / \mathrm{g}$ and8.43-9.14 $\log _{10} \mathrm{CFU} / \mathrm{g}$, respectively, in sourdough made from conventional or organic rye. Many reports have shown that the natural appearance of lactic acid bacteria and yeasts is the most important factor in making sourdough (Hanne and Ase, 2000; Meignen et al., 2001; Carnevali et al., 2007; Emanuele et al., 2009). Our results are the first to investigate the efficacy of a sourdough starter made from rice bran and raisins without artificial additives.

We also checked changes in the $\mathrm{pH}$ of sourdough with added rice bran and flour. The $\mathrm{pH}$ level of fermented raisin liquid was 3.68 and increased to 5.62 just after addition of rice bran and flour, and the $\mathrm{pH}$ levels of sourdough were not significantly different during fermentation of sourdough (5.92 for 2-step, and 6.02 for 3-step).

Changes in polyphenol and GABA contents during fermentation of the sourdough Figure 2 shows that repeated fermentation significantly increased the polyphenol content of
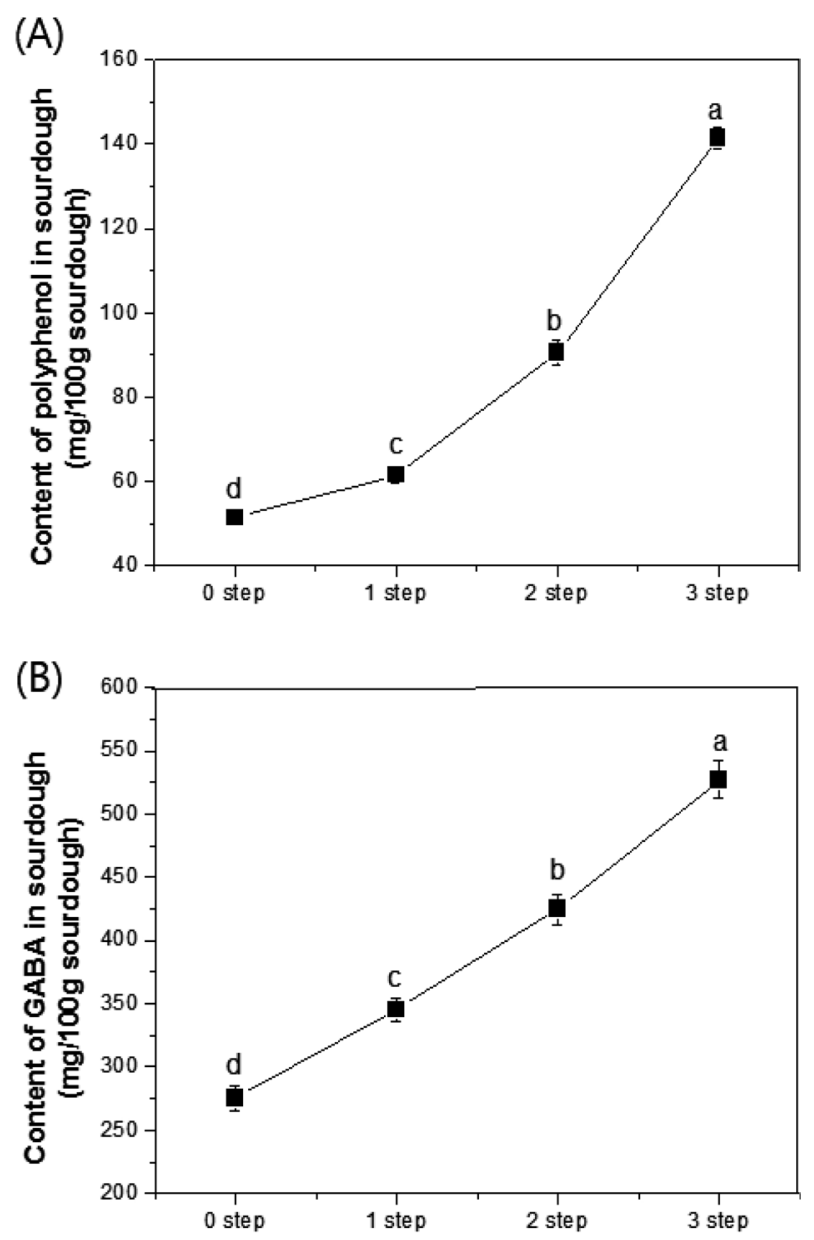

Fig. 2. Changes in polyphenol and GABA contents during fermentation of rice bran sourdough. (A) Polyphenol content. (B) GABA content. Dough mixed with fermented raisin liquid and rice bran (0-step), dough after 24 hours of fermentation from 0 -step (1step), dough after 12 hours of fermentation from 1-step (2-step), and dough after 6 hours of fermentation from 2-step (3-step). Each value represents mean \pm SD $(n=3),{ }^{\text {abcd }}$ Means with different superscripts are significantly different at a $5 \%$ significance level by Duncan's multiple range test. F-value is $1741.559^{* * *}$ $(* * * p<0.001)$. 
sourdough (Fig. 2 (A)), possibly due to fermentation of raisins. Polyphenols are present at a higher level in raisins compared to grapes, and lactic acid fermentation allows increased concentrations of total phenols, flavonoids, and anthocyanins in fruits (Williamson and Carughi 2010; Curiel et al., 2015). However, we could not exclude the possibility that polyphenol content might be affected by fermented rice bran in sourdough. In our previous study, polyphenol content of rice bran significantly increased after fermentation with yeast (Kim et al., 2011). Changes in the GABA content of sourdough during fermentation were similar to that of polyphenols (Fig. 2 (B). Flours itself have very low GABA level and their concentrations are various depending on their species. Coda et al. (2010) have been reported that the GABA content of twelve different flours had various endogenous concentrations of GABA, which varied from $3 \pm 1$ to $78 \pm 13 \mathrm{mg} / \mathrm{kg}$. Rice bran is known to be good source of GABA. GABA production significantly increased by fermentation with lactic acid bacteria and rice bran extracts (Kook et al., 2010). We also confirmed that GABA content in rice bran was increased by yeast fermentation. Rice bran fermented by yeast of $I$. orientalis MFST1 showed higher GABA content $(1002.8 \pm 18.2 \mathrm{mg} / 100 \mathrm{~g})$ compared to those of non-fermented normal rice bran $(634.0 \pm 15.1 \mathrm{mg} / 100 \mathrm{~g})$. Taken together, these findings led us to hypothesize that the increased GABA contents of sourdough may be mainly due to rice bran fermented in the sourdough.

As shown in Fig. 2, the GABA volume of sourdough using rice bran in this study is thought to be higher compared to general sourdough. There are several reports about GABA content in non-rice bran sourdough. Diana et al. reported that the GABA concentration in sourdough prepared using Lactobacillus brevis CECT 8183 was $98.2 \mathrm{mg} / 100 \mathrm{~mL}$ and similarly Coda et al. also showed GABA content of $103 \mathrm{mg} / 100 \mathrm{~g}$ in a study on the use of Lactococcus lactis subsp lactis PU1. (Diana et al., 2014; Coda et al., 2010).

\section{Conclusions}

Taken together, sourdough enriched with GABA could be rapidly and easily prepared through three-stage fermentation using rice bran and raisin liquid without artificial additives. These findings may enhance the health benefits and commercial value of rice bran as well as provide useful information for the effective use of milling by-products of rice.

Acknowledgements This work was supported by the 2012 Yeungnam University Research Grant

\section{References}

A.A.C.C. (1983). Approved methods of the AACC $8^{\text {th }}$ ed., Minnesota, USA.

A.O.A.C. (1984). Official Methods of Analysis of AOAC International $15^{\text {th }}$ ed., Washington D.C., USA.

Baek, S.B. (1990). Improving the quality of health breads. Patissier
B\&C WORLD, Seoul, Korea, pp. 40-60.

Banu, I., Vasilean, I., and Aprodu, I. (2010). Effect of Lactic Fermentation on Antioxidant Capacity of Rye Sourdough and Bread. Food Sci. Technol. Res., 16, 571-576

Bhanwar, S., Bamnia, M., Ghosh, M., and Ganguli, A. (2013). Use of Lactococcus lactis to enrich sourdough bread with $\gamma$-aminobutyric acid. Int. J. Food Sci. Nutr., 64, 77-81.

Carnevali, P., Ciati, R., Leporati, A., and Paese, M. (2007). Liquid sourdough fermentation: Industrial application perspectives, Food microbiology, 24, 150-154.

Chae, D.J., Lee, K.S., and Jang, K.H. (2011). Effect of amount of probiotics and yeast as starter on quality characteristics of sourdough bread. J. Korea Academia- Industrial cooperation Society, 12, 2652-2659.

Cho, N.J., Kim, H.I., and Kim, S.K. (1999). Effects of flour brew with Bifidobacterium bifidum as a natural bread improver. J. Korean Soc. Food Sci. Nutr., 28, 1275-1282.

Chung, H.C., Jeong, B.Y., and Han, G.D. (2011). Optimum conditions for combined application of Leuconostoc sp. and Saccharomyces sp. to sourdough. Food Sci. Biotechnol., 20, 1373-1379.

Coda, R., Rizzello, C.G., and Gobbetti, M. (2010). Sourdough bread enriched with $\gamma$-aminobutyric acid (GABA). A comparison of free amino acid, biogenic amine and acrylamide content in GABAenriched sourdough and commercial breads. Inter. J. food microb., 137, 236-45.

Curiel, J.A, Pinto, D., Marzani, B., Filannino, P., Farris, G. A., Gobbetti, M., and Rizzello, C. G. (2015). Lactic acid fermentation as a tool to enhance the antioxidant properties of Myrtus communis berries. Microb. Cell Fact., 14, 67

Diana, M., Rafecas, M., and QuílezFree, J. (2014). Free amino acids, acrylamide and biogenic amines in gammaaminobutyric acid enriched sourdough and commercial breads J. Cereal Sci., 60, 639644

Emanuele, Z., Cristiana, G., Lucia, A., Sara, S., Gloria, S., and Francesca, C. (2009). Microbiological and technological characterization of sourdoughs destined for bread-making with barley flour. Food microbiology, 26, 744-753.

Folin, O. and Denis, W. (1912). On phosphotungstic-phosphomolybdic compounds as color reagents. J. Biol. Chem., 12, 239-243.

Freund, W. and Starterkulturen und Sauerteigprodukte (2006). Handbuch Sauerteig. $6^{\text {th }}$ ed. in: Brandt, M.J., Gänzle, M.G., spicher, G., Behr's Verlag, Hamburg, Germany, pp. 353-375.

Hamelman, J. (2004). “Bread: a baker's book of techniques and recipes”. New York: John Wiley. pp. 6-362.

Hanne, R. and Ase, H. (2000). The microbial stability of two bakery sourdough made from conventionally and organically grown rye. Food microbiology, 17, 241-250.

Kim, D.Y. and Han, G. D. (2011). Ameliorating Effects of Fermented Rice Bran Extract on Oxidative Stress Induced by High Glucose and Hydrogen Peroxide in 3T3-L1 Adipocytes. Plant Foods for Human Nutrition, 66, 285-290.

Kim, M.Y. and Chun, S.S. (2008). Quality characteristics of rye mixed bread prepared with substitutions of naturally fermented raisin 
extract and sourdough. J. East Asian Soc. Dietary Life, 18, 87-94.

Kook, M.C., Seo, M.J., Cheigh, C.I., Pyun, Y.R., Cho, S.C., and Park, H. (2010). Enhanced production of gamma-aminobutyric acid using rice bran extracts by Lactobacillus sakei B2-16. J. Microbiol. Biotechnol., 20, 763-766.

Kwak, E.J. (2010). Development of brown colored rice tea with high GABA content. J. Korean Soc. Food Sci. Nutr., 39, 1201-1205.

Lee, J.H., Kwak, E.J., Kim, J.S., Lee, K.S., and Lee, Y.S. (2007). A study on quality characteristics of sourdough breads with addition of red yeast rice. J. Korean Soc. Food Sci. Nutr., 36, 785-793.

Lee, Y.S., Joo, E.Y., and Kim, N.W.(2006). Polyphenol contents and antioxidant activity of lepista nuda. Korean J. Food Sci. Nutr., 35, 1309-1314.

Leventhal, A.G., Wang, Y.C., Pu, M.L., Zhou, Y.F., and Ma, Y. (2003). GABA and its agonists improved visual cortical function in senescent monkeys. Science, 300, 812-815.

Lin, K.H., Lu, W.J., Wang, S.H., Fong, T.H., Chou, D.S., Chang, C.C., Chang, N.C., Chiang, Y.C., Huang, S.Y., and Sheu, J.R.(2014). Characteristics of endogenous $\gamma$-aminobutyric acid (GABA) in human platelets: functional studies of a novel collagen glycoprotein VI inhibitor. J. Mol. Med. (Berl)., 92, 603-614.

Meignen, B., Onno, B., Gelinas, P., Infantes, M,. Guilois, S., and Cahagnier, B. (2001). Optimization of sourdough fermentation with
Lactobacillus brevis and baker's yeast. Food microbiology, 18, 239-245.

Moon, S.H., Lee, K.B., and Han, M.K. (2010). Comparison of GABA and vitamin contents of germinated brown rice soaked in different soaking solution. Korean J. Food \& Nutr., 23, 500-515.

Nakagawa, T., Yokozawa, T., Kim, H.J., and Shibahara, N.(2005) Protective effects of gamma-aminobutyric acid in rats with streptozotocin-induced diabetes. J. Nutr. Sci. Vitaminol. (Tokyo), 51, 278-282.

Oberg, C.J., Davis, L.H., Richardson, G.H., and Ernstrom, C.A. (1986). Manufacture of chedder cheese using proteinase-negative mutants of Streptococcus cremoris. J. Dairy Sci., 69, 2975-2981.

Shin, E.H. and Kim, K.J. (2001). Effect of lactic acid bacteria preferment addition on the quality of white bread. Journal of Research Ulsan College, 27, 459-470.

Stanley, BG. (2012). GABA: a cotransmitter linking leptin to obesity prevention. Endocrinology, 153, 2057-2058.

Thiele, C., Gänzle, M. G., and Vogel, R. F. (2002). Contribution of Sourdough Lactobacilli, Yeast, and Cereal Enzymes to the Generation of Amino Acids in Dough Relevant for Bread Flavor. Cereal Chem., 79, 45-51.

Williamson, G1. and Carughi, A. (2010). Polyphenol content and health benefits of raisins. Nutr. Res., 30, 511-519. 